\title{
Changes in metabolism of cerebral glucose after stereotactic leukotomy for refractory obsessive- compulsive disorder: a case report
}

\author{
F Biver, S Goldman, A François, C De La Porte, A Luxen, B Gribomont, F Lotstra
}

\begin{abstract}
Brain glucose metabolism was investigated with PET and $\left[{ }^{18}\right.$ F]fluorodeoxyglucose, before and after a bifrontal stereotactic leukotomy in a 37 year old woman with refractory obsessive-compulsive disorder. A bilateral decrease in glucose metabolism was found in the orbital frontal cortex after psychosurgery. Glucose metabolism was decreased to a lesser degree in Brodmann's area 25 , in the thalamus, and in the caudate nucleus. Clinical improvement in obsessive-compulsive disorder after stereotactic tractotomy seems to be associated with metabolic changes in the brain, in particular, in the orbital part of the frontal lobe.
\end{abstract}

(F Neurol Neurosurg Psychiatry 1995;58:502-505)

Keywords: glucose metabolism; obsessive-compulsive disorder; stereotactic leukotomy

Several PET studies with $\left[{ }^{18} \mathrm{~F}\right]$ fluorodeoxyglucose (FDG) as a tracer have been performed in obsessive-compulsive disorder. Studies have associated untreated obsessivecompulsive disorder with increased glucose metabolism in the orbital frontal cortex. ${ }^{1}$ Blood flow studies have provided results consistent with these metabolic changes in the orbital cortex. ${ }^{2}$ Metabolism in the caudate nucleus and cingulate cortex have also been reported to be significantly increased in patients with obsessive-compulsive disorder. A recent blood flow study has shown a positive correlation between symptom intensity and blood flow in different brain regions including the right inferior frontal gyrus and the caudate and lenticular nuclei. ${ }^{3}$ These results suggest that obsessivecompulsive disorder may be associated with brain dysfunction which involves limbicfrontal-basal ganglia circuits. Both pharmacological and behavioural treatments of obsessive-compulsive disorder seem to normalise functional imaging results. ${ }^{14}$ The aim of our study was to describe the metabolic changes after a partially successful stereotactic leukotomy for refractory obsessive-compulsive disorder in a 37 year old woman.

\section{Case report}

PATIENT HISTORY

This 37 year old woman had obsessive-compulsive disorder according to DSM-IV criteria. First symptoms appeared when the patient was 8 years old and consisted of symmetry obsessions and ordering compulsions associated with facial tics. The psychiatric symptoms slowly progressed until the age of 18 , when, after renal surgery for lithiasis, the symptoms abruptly worsened with severe checking compulsions. She worked in a day nursery after high school. When she was 22 years old, she stopped working and obtained an invalidity allowance because of her psychiatric symptoms and repeated admissions to hospital. By the age of 34 , her mental state was such that she needed permanent care in a psychiatric institution. She made multiple impulsive suicide attempts and she had a period of benzodiazepine and alcohol misuse between the ages of 22 and 27 .

At admission, she was experiencing aggressive obsessions (fears to injure other people, violent and horrific images), contamination obsession (concern with dirt and germs), hoarding obsession (clothes hoarding), obsessions with need of symmetry and exactness. She described compulsive rituals of cleaning and washing and numerous checking compulsions. She had to repeat short sentences, and to count the objects in her environment and the number of sentences, words, vowels, and consonants during conversation. She presented ordering compulsions (furniture, household items, clothes) and, among miscellaneous compulsions, ritualised eating behaviours, self-damaging behaviours, and need to touch objects. The patient requires close staff supervision for most daily activities and support for minor decision making. Her score on the NIMH global obsessive-compulsive scale (scores from 0 to 15 ) was 14 (very severe symptoms). The score on the 10 first items of the Yale-Brown obsessive-compulsive scale (Y-BOCS, scores from 0 to 40 ) was 38 . The patient also met criteria for a major depressive disorder with suicidal ideation. Electroconvulsive treatment (10 courses) was given and led to partial remission of the depressive state but without an effect on obsessive-compulsive disorder.

Psychosurgery intervention was proposed to the patient who had never improved 
Figure 1 MRI image showing the lesion produced by the stereotactic leukotomy.

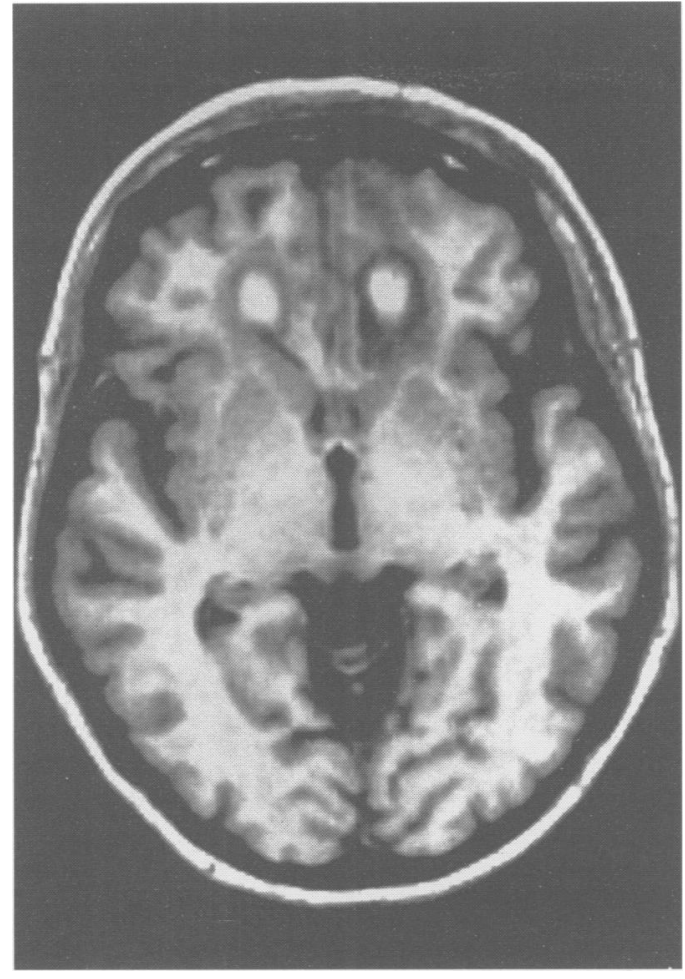

during different kinds of psychotherapy (behavioural, psychoanalytic, systemic) or under different successive drug treatments (clomipramine (300 mg/day), fluoxetine ( $80 \mathrm{mg} /$ day), fluvoxamine ( $300 \mathrm{mg} /$ day)). Preoperative CT and neuropsychological testing (memory, cognitive tasks, learning, language) were normal. The patient had received fluvoxamine $(300 \mathrm{mg} /$ day) for five months without any therapeutic effect on obsessive-compulsive disorder symptoms when the operation was performed and this treatment was maintained after the intervention.

\section{OPERATIVE TECHNIQUE}

A bifrontal stereotactic tractotomy was performed according to Knight's operative technique ${ }^{5}$ in the most posteroinferior part of the frontal lobe. Electrically insulated thermistor electrodes were positioned in the most posterobasal part of the frontal white matter through bilateral frontal burr holes just above the frontal sinus (as seen radiologically) and $1.5 \mathrm{~cm}$ to either side of the midline. Coordinates of the three targets were located $1 \mathrm{~cm}$ above the anterior clinoid in the horizontal plane and $5 \mathrm{~mm}$ anterior to the anterior wall of the sella turcica in the sagittal plane. In the frontal plane, the targets were located bilaterally 12,15 , and $18 \mathrm{~mm}$ from the midline (three trajectories). The electrodes were heated to $80^{\circ} \mathrm{C}$ for one minute and four lesions were made on each trajectory at the level of the target $(0 \mathrm{~mm})$ and at $-6,-12$, and $-18 \mathrm{~mm}$. This procedure led to an estimated $2 \mathrm{~cm}$ long, $1 \mathrm{~cm}$ wide, and $4 \mathrm{~mm}$ thick lesion.

PET PROCEDURE

The first and second PET studies were performed under chronic treatment with fluvoxamine ( $300 \mathrm{mg} /$ day) four weeks before and 14 weeks after psychosurgery.

The PET investigations were made in a quiet and dimly lit room. The patient remained in a supine resting state with her eyes closed. She received an intravenous bolus of $6 \mathrm{mCi}$ FDG. The activity of the tracer in the brain was measured with an eight ring PET camera (CTI-Siemens 933-08-12, Knoxville, TN, USA) providing fifteen $7 \mathrm{~mm}$-thick adjacent slices through the whole brain. The spatial resolution of the images is about $5 \mathrm{~mm}$ full width at half maximum. The patient was placed in the PET camera to obtain slices parallel to the canthomeatal line. Using a source filled with an $\left[{ }^{18} \mathrm{~F}\right]$-fluoride solution, a 10 minute transmission scan was performed and, 40 minutes after the FDG injection, a 20 minute emission scan was obtained. Plasma (21 arterial blood samples) and brain radioactivity were corrected for decay and PET images were corrected for attenuation with transmission scan data. With corrected emission scan data, plasma radioactivity time course, and plasma glucose concentration, cerebral metabolic rates of glucose (CMRglu) were calculated, according to the Phelps-Sokoloff model, in 59 regions of interest (27 bilateral and five median) delineated on PET slices from a template based on a human brain stereotaxic atlas. Relative CMRglu values were calculated by dividing each CMRglu value by the whole brain CMRglu value.

\section{CLINICAL RESULTS}

After psychosurgery, intensity, and frequency of compulsive rituals diminished such that the patient became independent for dressing, bathing, and limited household duties. Under controlled conditions, she resumed some social activities and relationships. Nevertheless, the patient reported poor improvement of her obsessions. Her cognitive abilities did not differ from preoperative testing (IQ 102). Three months after the surgical intervention, NIMH scale and Yale-Brown scale scores were 10 and 30 respectively.

\section{NEUROIMAGING}

The postoperative CT and MRI showed two bifrontal oval lesions in the posterobasal white matter (fig 1).

We found a CMRglu increase in the whole brain of $9 \%$ on the second PET compared with the first. This increase was below the limit of significance set at $15 \%$, based on the inter-PET variation found in 13 normal subjects tested in our centre. In the basal part of the frontal cortex (10 different regions of interest), the decrease in relative CMRglu values ranged from 3 to $29 \%$ (fig 2). The relative metabolic decrease was the most pronounced in the medial part of the frontal basal cortex (table). We also found decreased relative CMRglu values in the left and right thalamus, caudate nucleus, and Brodmann's area 25 of the cingulate cortex (table). In the superior part of the frontal 
Figure 2 Top row: PETFDG brain slices parallel to the canthomeatal line, $14 \mathrm{~mm}$ above the caudate nucleus (left) and at the level of the orbital cortex (right), before stereotactic tractotomy. Bottom row:

PET-FDG slices obtained after tractotomy, at a level similar to the top row. The relative metabolism is

unchanged in the superior frontal, parietal and

posterior cingulate cortices (left). Relative

hypometabolism is manifest in the orbital cortex (right, top of the image). The right side of the brain is on the left side of the image; colour scale: from $0 \%$

(bottom) to 95\% (top) of the maximal glucose

metabolic rate pixel value in the whole scan.

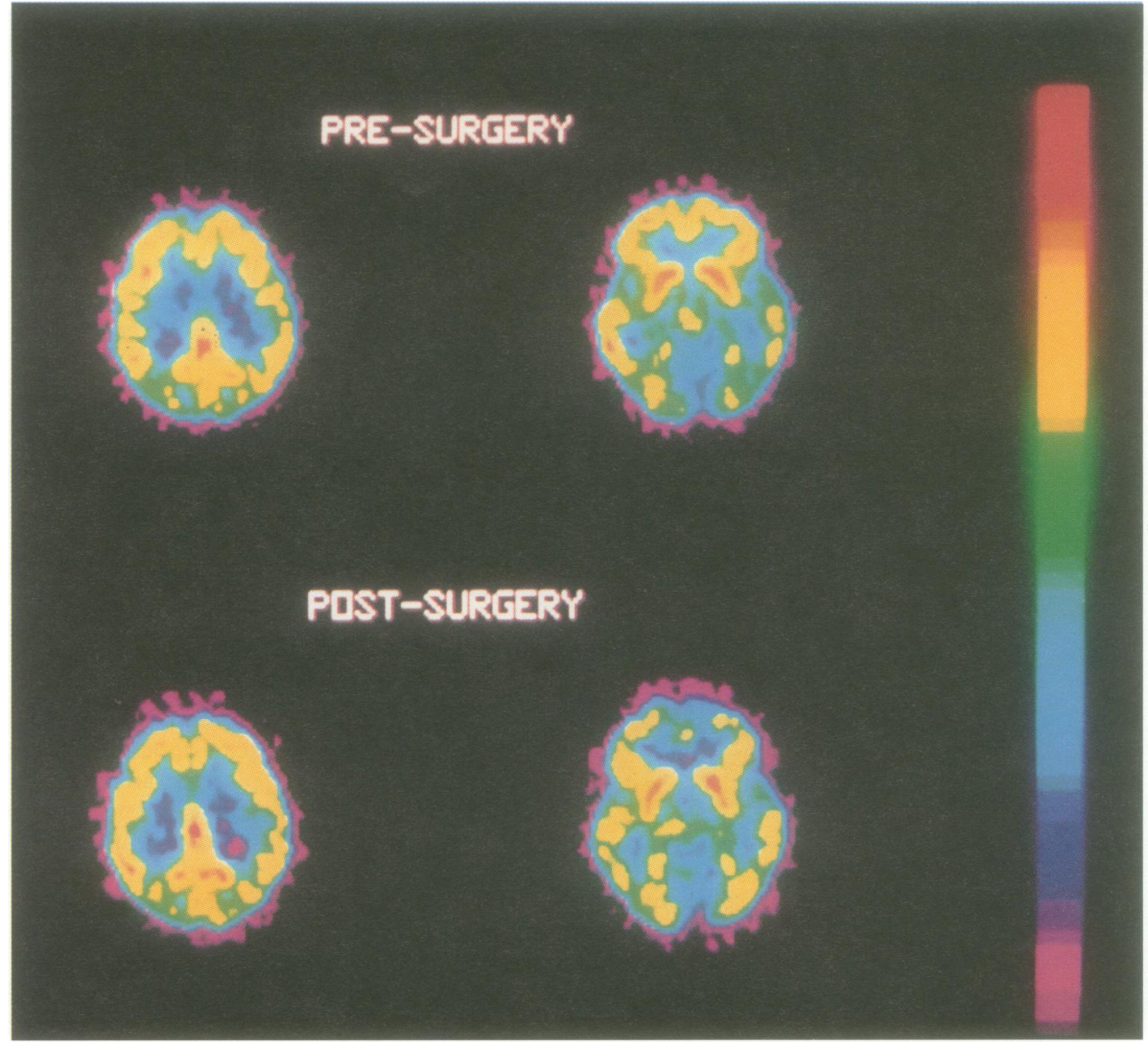

Absolute ( $(\mathrm{mol} / \mathrm{min} / 100 \mathrm{~g}$ ) and relative cerebral metabolic rate of glucose (CMRglu)

\begin{tabular}{|c|c|c|c|c|c|c|}
\hline Btain area & & $\begin{array}{l}\text { CMRglu } \\
\text { preoperation }\end{array}$ & $\begin{array}{l}\text { CMRglu } \\
\text { postoperation }\end{array}$ & $\begin{array}{l}\text { Relative CMRglu } \\
\text { preoperation }\end{array}$ & $\begin{array}{l}\text { Relative CMRglu } \\
\text { postoperation }\end{array}$ & $\begin{array}{l}\% \text { Change relative } C M R g l u \\
\text { post } v \text { preoperation }\end{array}$ \\
\hline \multicolumn{7}{|l|}{ Frontal cortex: } \\
\hline Medial basal & & $22 \cdot 08$ & $17 \cdot 12$ & $1 \cdot 19$ & 0.84 & $-29 \cdot 4$ \\
\hline \multirow{2}{*}{ Lateral basal } & $\mathrm{L}$ & $21 \cdot 51$ & $18 \cdot 53$ & $1 \cdot 16$ & 0.91 & $-21 \cdot 6$ \\
\hline & $\mathbf{R}$ & $19 \cdot 37$ & 18.99 & 1.05 & 0.93 & $-10 \cdot 8$ \\
\hline \multirow{2}{*}{ Dorsolateral } & $\mathrm{L}$ & 22.99 & $27 \cdot 17$ & $1 \cdot 24$ & 1.34 & $7 \cdot 5$ \\
\hline & $\mathbf{R}$ & $22 \cdot 01$ & $26 \cdot 44$ & $1 \cdot 19$ & $1 \cdot 30$ & $9 \cdot 3$ \\
\hline \multirow[t]{2}{*}{ Cingulate cortex } & $\mathrm{L}$ & $15 \cdot 22$ & 15.95 & $0 \cdot 82$ & 0.78 & $-4 \cdot 6$ \\
\hline & $\overline{\mathbf{R}}$ & $17 \cdot 36$ & $15 \cdot 28$ & 0.94 & 0.75 & $-19 \cdot 9$ \\
\hline \multirow[t]{2}{*}{ Parietal cortex } & $\mathrm{L}$ & $22 \cdot 32$ & $25 \cdot 87$ & $1 \cdot 21$ & 1.27 & $5 \cdot 5$ \\
\hline & $\mathbf{R}$ & $22 \cdot 54$ & 25.95 & 1.22 & 1.28 & $4 \cdot 8$ \\
\hline \multirow[t]{2}{*}{ Temporal cortex } & $\mathrm{L}$ & $19 \cdot 62$ & $22 \cdot 18$ & 1.06 & 1.09 & $2 \cdot 9$ \\
\hline & $\mathbf{R}$ & $19 \cdot 54$ & $22 \cdot 34$ & 1.06 & $1 \cdot 10$ & $4 \cdot 0$ \\
\hline \multirow[t]{2}{*}{ Occipital cortex } & $\mathrm{L}$ & $23 \cdot 77$ & $27 \cdot 56$ & $1 \cdot 28$ & 1.36 & 5.5 \\
\hline & $\mathbf{R}$ & $23 \cdot 35$ & $28 \cdot 44$ & 1.26 & 1.40 & $10 \cdot 8$ \\
\hline \multirow[t]{2}{*}{ Thalamus } & $\mathrm{L}$ & $25 \cdot 01$ & $24 \cdot 82$ & 1.35 & $1 \cdot 22$ & $-9 \cdot 7$ \\
\hline & $\overrightarrow{\mathbf{R}}$ & $26 \cdot 29$ & $24 \cdot 24$ & 1.42 & $1 \cdot 19$ & $-16 \cdot 1$ \\
\hline \multirow[t]{2}{*}{ Caudate } & L & 22.06 & $22 \cdot 83$ & $1 \cdot 19$ & $1 \cdot 12$ & $-5 \cdot 8$ \\
\hline & $\mathbf{R}$ & $23 \cdot 24$ & $23 \cdot 64$ & 1.26 & $1 \cdot 16$ & $-7 \cdot 4$ \\
\hline
\end{tabular}

$\mathrm{L}=$ left; $\mathbf{R}=$ right.

lobe, the increase in relative CMRglu ranged from 4 to $9 \%$ (fig 2 ).

\section{Discussion}

This case showed that the metabolic consequence of the selective stereotactic tractotomy as treatment for severe obsessivecompulsive disorder consisted of hypometabolism in the orbital cortex and area 25 of the cingulate cortex. Less severe metabolic changes were also found in the thalamus and caudate nucleus. Surgical intervention resulted in partial clinical improvement.

Disruptions of thalamocortical pathways are reported to improve the symptoms of obsessive-compulsive disorder. Our findings of reduced metabolism in the orbital cortex, in the cingulate cortex, and in the caudate nucleus, are consistent with PET findings obtained in patients with obsessive-compulsive disorder with pharmacological or behavioural treatments that effectively decrease the symptoms. ${ }^{5}$ The metabolic 
changes associated with clinical improvement in our patient compare with the findings of increased orbital frontal and caudate activity in untreated patients with obsessive-compulsive disorder at rest or during symptom induction. ${ }^{13}$ Similarly, the postsurgical metabolic changes in our patient were the most pronounced in the medial part of the orbital cortex, a region where a blood flow study showed the most pronounced increase during obsessive-compulsive disorder. ${ }^{2}$

As recently shown in a patient with Gilles de la Tourette's syndrome, ${ }^{6}$ this study shows that PET may be used to localise and quantify the changes in neuronal activity induced by functional neurosurgery for psychiatric or neurological disorders.

This study was supported by research grants 9.4503 .91 from the Belgian National Lottery and 3.4508.92 and 3.4505.92 from the Funds for Medical Scientific Research (FRSM, Belgium). Françoise Biver is a research fellow of the National Funds for Scientific Research (FNRS, Belgium).

1 Baxter LR, Schwartz JM, Mazziotta JC, et al. Cerebral glucose metabolic rates in non-depressed patients with glucose metabolic rates in non-depressed patients with
obsessive-compulsive disorder. Am $\mathcal{f}$ Psychiatry 1988; 145:1560-63.

2 Machlin S, Harris G, Pearlson G, et al. Elevated medialfrontal cerebral blood flow in obsessive-compulsive patients: SPECT study. Am $\mathcal{f}$ Psychiatry 1991;148: 1240-2.

3 Mcguire PK, Bench CJ, Frith CD, Marks IM, Frackowiak RSJ, Dolan RJ. Functional anatomy of obsessive-compulsive phenomena. Br $\mathcal{F}$ Psychiatry 1994;164:459-68.

4 Baxter LR, Schwartz JM, Bergman KS, et al. Caudate glucose metabolic rate changes with both drug and behavior therapy for obsessive-compulsive disorder. Arch Gen Psychiatry 1992;49:681-9.

5 Knight, GG Bifrontal stereotaxic tractotomy in the substantia innominata. In: Hitch cock E, Laitinen L, vabstantia innominata. In: Hitchcock E, Laitinen L, Vaernet K, eds. Psychosurgery. Springfield: CC Thomas,

6 Sawle GV, Lees AJ, Hymas NF, Brooks DJ, Frackowiak RSJ. The metabolic effects of limbic leucotomy in Gilles de la Tourette syndrome. F Neurol Neurosurg Psychiatry 1993;56:1016-9. 